\title{
Anti-MUC-1 Monoclonal Antibody
}

National Cancer Institute

\section{Source}

National Cancer Institute. Anti-MUC-1 Monoclonal Antibody. NCI Thesaurus. Code C29983.

A monoclonal antibody recognizing human mucin, a cell surface antigen encoded by the MUC-1 gene. In normal tissue, mucin exists as heavily glycosylated form, while tumorassociated mucin molecules are hypo-glycosylated. Hypo-glycosylation exposes the normally cryptic tandem peptide repeats in cancer-associated mucin, thereby allows antigen-antibody interaction with MUC-1 antibody. As a result, the MUC-1 antibody inhibits the initiation of the immunosuppressive cascade triggered by mucin, including production and secretion of prostag landin E2 (PGE2), followed by VEGF induction and suppression of natural killer cell, lymphokine-activated killer cell and cytotoxic T cell activity. 